\title{
DESENVOLVIMENTO DO PORTA-ENXERTO DE TANGERINEIRA 'CLEÓPATRA'
}

\author{
MARIA DO CÉU MONTEIRO DA CRUZ², OSCAR MARIANO HAFLE ${ }^{3}$ \\ JOSÉ DARLAN RAMOS ${ }^{4}$, PATRÍCIA DE SIQUEIRA RAMOS 5
}

RESUMO- Perdas por percolação e lixiviação são evidentes em substratos para produção de mudas cítricas, notadamente na primeira fase, antes da repicagem dos porta-enxertos. Assim, o trabalho foi realizado com o objetivo de avaliar os efeitos do polímero hidroabsorvente e do lithothamnium sobre o desenvolvimento da tangerineira 'Cleópatra' até a repicagem. A semeadura foi realizada em tubetes $(50 \mathrm{~mL})$ contendo substrato comercial, acrescido dos tratamentos: 2 doses de lithothamnium $\left(0\right.$ e $\left.5 \mathrm{~g} \mathrm{~L}^{-1}\right)$ e 5 doses do polímero $\left(0 ; 15 ; 30 ; 45\right.$ e $\left.60 \mathrm{~g} \mathrm{~L}^{-1}\right)$. Foi utilizado o delineamento inteiramente casualizado, em esquema fatorial $5 \times 2$, com 4 repetições e sete plantas por parcela. Para avaliar o desenvolvimento das mudas, as seguintes características foram determinadas: comprimento da parte aérea e do sistema radicular $(\mathrm{cm})$, número de folhas por planta e matéria seca da parte aérea e das raízes $(\mathrm{mg})$. A incorporação do polímero hidroabsorvente ao substrato favoreceu o desenvolvimento de porta-enxertos de tangerineira 'Cleopatra' na fase inicial de produção. A dose de polímero utilizada não deve ultrapassar $50 \mathrm{~g} \mathrm{~L}^{-1}$ para evitar o excesso de umidade no substrato e a deficiência de aeração do sistema radicular. A adição do lithothamnium ao substrato de cultivo proporcionou o melhor desenvolvimento das mudas. Termos para indexação: Citrus reshni, propagação, citricultura, polímero hidroabsorvente, lithothamnium.

\section{DEVELOPMENT OF TANGERINE TREE ROOTSTOCK 'CLEÓPATRA'}

ABSTRACT-Losses by percolating and leaching are evident on substrates for citrus seedling production, notably in the initial phase, until rootstock transplant. The research was carried out with the aim of evaluating the effects of hydro-absorbent polymer and lithothamnium on 'Cleópatra' tangerine tree development until transplant. The sowing was done in stiff plastic tubes $(50 \mathrm{~mL})$ filled up with commercial substrate and treatments: two doses of lithothamnium $\left(0\right.$ and $\left.5 \mathrm{~g} \mathrm{~L}^{-1}\right)$ and five doses of polymer $(0,15,30,45$ and 60 $\left.\mathrm{g} \mathrm{L}^{-1}\right)$. The experimental design was entirely randomized, in a factor arrangement $5 \times 2$, with four replications and seven plants by plot. The seedling development was evaluated with the following characteristics: length of the aerial part and roots system $(\mathrm{cm})$, number of leaves per plant and dry matter of the aerial part and roots $(\mathrm{mg})$. The hydro-absorbent polymer incorporation to the substrate favored 'Cleópatra' rootstocks development on the initial production phase. The doses should not overcome $50 \mathrm{~g} \mathrm{~L}^{-1}$ to avoid excess of water levels in substrate and difficult roots system aeration. The Lithothamnium incorporation to the substrate provided better development.

Index terms: Citrus reshni, propagation, Citriculture, hydro-absorbent polymer, lithothamnium.

\section{INTRODUÇÃO}

O sistema de produção de mudas cítricas passou por mudanças significativas nos últimos anos devido às inúmeras doenças causadas por fungos de solos que comprometem sua qualidade sanitária.

O método convencional de produção de mudas cítricas, utilizando recipientes em ambientes controlados, além das inúmeras vantagens oferecidas em relação ao controle de contaminação por fungos e nematóides, ao bom desenvolvimento do sistema radicular e à boa nutrição, visa também a acelerar o desenvolvimento das mudas mediante o uso de substratos especialmente preparados, acrescidos de adubações complementares.

Nesse sistema, as adubações nitrogenadas são as principais e mais difíceis nos programas de fertilização, pois a alta densidade de plantas e o rápido crescimento vegetativo tornam necessário aumentar a eficiência de aplicação dos fertilizantes para reduzir os custos de produção e minimizar a contaminação da água do subsolo (Maust \& Williansom, 1994).

A lavagem ininterrupta do substrato, pela necessidade de irrigação freqüente dos tubetes utilizados como suportes, causa perdas significativas de alguns nutrientes, principalmente o nitrogênio.

Neste sentido, a utilização de polímeros hidroabsorventes favorece a retenção de água no substrato, reduzindo a quantidade de água aplicada, e a incorporação do Lithothamnium aumenta a disponibilidade dos nutrientes, antecipando o tempo de formação das mudas.

O Lithothamnium é um produto derivado de algas marinhas calcárias que apresenta em sua composição $\mathrm{Ca}, \mathrm{Mg}, \mathrm{S}$, $\mathrm{Cl}$, Mo e Fe, o que favorece as condições de fertilidade do solo e/ ou potencializa o uso do fertilizante químico por sua ação corretiva da acidez (Melo \& Furtini Neto, 2003).

1(Trabalho 136-07). Recebido em: 24-05-2007. Aceito para publicação em: 14-12-2007.

${ }^{2}$ Eng.Agr., Doutoranda em Fitotecnia-UFLA. Cx. Postal 37, Lavras-MG, CEP 37200-000. Bolsista do CNPq, m_mariceu@yahoo.com.br.

${ }^{3}$ Doutorando em Fitotecnia-UfLA. Cx. Postal 37, Lavras-MG, CEP 37200-000. Professor da Escola Agrotécnica Federal de Sousa-PB omhafle@yahoo.com.br.

${ }^{4}$ Eng. Agr., Dr., Professor DAG/UfLA, Cx. Postal 37, Lavras-MG, CEP 37200-000, darlan@ufla.br.

${ }^{5}$ Bacharel em Ciência da Computação, Doutoranda em Estatística e Experimentação Agropecuária, UFLA, siqueirapaty@gmail.com. 
Os trabalhos com uso de Lithothamnium têm apresentado bons resultados na cultura do feijoeiro, favorecendo o crescimento e a produção (Melo \& Furtini Neto, 2003), e na formação de mudas de maracujazeiro-amarelo (Mendonça et al., 2006). Entretanto, pouco se conhece a respeito da aplicação do Lithothamnium em espécies frutíferas, onde o substrato é o fator mais importante no desenvolvimento das mudas na fase inicial.

As propriedades dos polímeros hidroabsorventes proporcionam melhorias nas propriedades físicas e hidráulicas do solo ou do substrato de cultivo. A sua incorporação no solo otimiza a disponibilidade de água, reduz as perdas por percolação e lixiviação de nutrientes, e melhora a aeração e drenagem do solo, acelerando o desenvolvimento do sistema radicular e da parte aérea das plantas (Lamont \& O'Connell, 1987).

Segundo Oliveira et al. (2004), o uso de polímero hidroabsorvente contribuiu para aumentar a retenção de água nos solos de textura franco-argilo-arenosa e argilosa até o potencial matricial de -1,0 MPa, sendo observada maior retenção de água nos solos com maior concentração do polímero.

Vários trabalhos foram desenvolvidos com a aplicação de polímeros como redutores das perdas de nutrientes e na retenção de água no solo. Azevedo et al. (2002), estudando a eficiência de polímeros no fornecimento de água para o cafeeiro, constatou que seu efeito sobre as características: altura de plantas, massa seca da parte aérea e massa seca das raízes das plantas foi significativo, podendo-se afirmar que a presença de polímeros no substrato permite ampliar os intervalos entre irrigações, sem comprometer o crescimento da planta por déficit de água.

Ao contrário, na produção de mudas cítricas em tubetes, a adição de polímero hidroabsorvente mostrou-se prejudicial ao desenvolvimento das mudas na fase inicial devido a doses excessivas do polímero utilizado (Vichiato et al., 2004).

No Brasil, alguns polímeros sintéticos hidroabsorventes estão sendo utilizados na produção de frutas, hortaliças e mudas de diversas espécies. No entanto, os dados científicos de seu uso são restritos, e os resultados são variáveis, devido às diferenças existentes entre as cultivares, doses utilizadas do produto, condições ambientais, dificultando a extrapolação de resultados para situações específicas, como o cultivo em tubetes, visando a elevar a capacidade de retenção de água do substrato e adequada disponibilidade de nutrientes necessários ao bom desenvolvimento de porta-enxertos.

O trabalho foi realizado com o objetivo de avaliar o desenvolvimento do porta-enxerto de tangerineira 'Cleópatra' até a repicagem, com a incorporação de Lithothamnium e de polímero hidroabsorvente ao substrato.

\section{MATERIAL E MÉTODOS}

O trabalho foi conduzido durante o período de julho a novembro de 2006, sob telado, no Pomar do Setor de Fruticultura do Departamento de Agricultura da Universidade Federal de Lavras (UFLA), Lavras-MG.

Foi utilizado o delineamento inteiramente casualizado, com esquema fatorial $5 \times 2$, sendo os fatores constituídos pelas 5 doses do polímero hidroabsorvente (Ecogel $\left.\mathrm{VEG}^{\circledR}\right): 0 ; 15 ; 30 ; 45$ e $60 \mathrm{~g} \mathrm{~L}^{-1}$ e 2 doses de lithothamnium (Afertil ${ }^{\circledR}$ ): 0 e $5 \mathrm{~g} \mathrm{~L}^{-1}$, com quatro repetições e 7 plantas por unidade experimental.

Ao substrato, foram incorporados o polímero hidroabsorvente e o lithothamnium, efetuando-se a homogeneização das misturas ao Bioplant ${ }^{\circledR}$. Esse substrato é constituído de farelado grosso, com capacidade de retenção de água mínima de $150 \%$ em massa. Posteriormente, foi realizado o preenchimento dos tubetes $(50 \mathrm{~mL})$ e irrigação para a realização da semeadura.

As sementes de tangerineira 'Cleópatra' (Citrus reshni Hort. ex Tan) foram extraídas de frutos maduros, lavadas em água corrente, colocadas para secar à sombra por 3 dias. Em seguida, foram semeadas, colocando-se duas sementes por tubete.

As bandejas com os tubetes foram deixadas sob telado coberto por sombrite com $50 \%$ de luminosidade. As irrigações foram realizadas diariamente, suficientes para manter a umidade do substrato nos tubetes próximo à capacidade de campo (umidade retida logo após perder por drenagem seu excesso de água), conforme estimado em ensaios anteriores, mediante a reposição da quantidade de água consumida, em um determinado intervalo de tempo, pela cultura em plena atividade vegetativa.

Após 120 dias, quando as mudas apresentavam altura adequada, em torno de $10 \mathrm{~cm}$, para serem transplantadas para os citropotes, foram avaliadas as seguintes características: comprimento da parte aérea $(\mathrm{cm})$, comprimento do sistema radicular $(\mathrm{cm})$, número de folhas por planta e matéria seca da parte aérea e das raízes $(\mathrm{mg})$.

O comprimento da parte aérea das mudas foi obtido, medindo-se a distância entre o colo e o ápice da muda. $\mathrm{O}$ comprimento da raiz foi obtido, medindo-se a distância entre o colo e a extremidade da raiz. A massa seca da parte aérea e da raiz foi obtida após secagem em estufa de circulação forçada de ar a $60{ }^{\circ} \mathrm{C}$, até atingirem peso constante, procedendo-se à pesagem em balança analítica.

Os dados obtidos foram submetidos à análise de variância para verificar a interação entre os tratamentos e a regressão polinomial, utilizando as doses do polímero como variável independente e as características avaliadas como variáveis dependentes. Os modelos foram escolhidos com base na significância dos coeficientes de regressão, utilizando-se do teste ' $t$ ', a $5 \%$ de probabilidade

\section{RESULTADOS E DISCUSSÃO}

Houve efeito significativo da aplicação do polímero ao substrato para todas as características avaliadas, e do lithothamnium sobre o número de folhas e massa seca da parte aérea e massa seca das raízes.

A incorporação das diferentes doses do polímero ao substrato favoreceu o crescimento inicial das mudas da tangerineira 'Cleópatra', em ambas as situações, com e sem a adição de lithothamniu ao substrato (Figura 1). Nas plantas que receberam a aplicação de Lithothanium, o maior comprimento da parte aérea foi alcançado com a dose de $49,31 \mathrm{~g} \mathrm{~L}^{-1}$ de polímero, com $8,12 \mathrm{~cm}$ de altura, o que correspondeu a um aumento de 
35,4\% em relação à testemunha. Sem a adição de Lithothamnium, a dose do polímero que correspondeu ao maior comprimento da parte aérea da tangerineira 'Cleópatra' foi a de 44,95 g L-1, com $7,27 \mathrm{~cm}$ de altura, o que representou o acréscimo de $22,1 \%$. Resultados semelhantes foram observados por Vichiato et al. (2004) com a aplicação de polímero hidroabsorvente em portaenxerto de tangerineira 'Cleópatra' que também observaram menores valores nas mudas que receberam doses excessivas do polímero.

Para o comprimento do sistema radicular, não houve diferenças com relação à aplicação do lithothamnium (Figura 2). Para o polímero, as doses que corresponderam aos maiores valores estimados foram $42,7 \mathrm{~g} \mathrm{~L}^{-1}$ e $32,9 \mathrm{~g} \mathrm{~L}^{-1}$ do polímero, com $6,5 \mathrm{~cm}$ e $6,3 \mathrm{~cm}$, o que representou aumentos de $54,2 \%$ e $37,6 \%$, respectivamente, nas mudas sem e com a incorporação do lithothamnium.

Esse resultado apresentado, em relação ao comprimento do sistema radicular, pode ser atribuído ao excesso de umidade observado nos substratos que receberam as maiores doses do polímero, o que também influenciou no desenvolvimento da parte aérea, provavelmente pela menor aeração, o que compromete a absorção iônica e a disponibilidade de nutrientes.

Não houve efeito do polímero hidroabsorvente sobre o número de folhas nas mudas que receberam a incorporação do Lithothamnium. Entretanto, o número de folhas das plantas que não receberam a aplicação do Lithothamnium apresentou comportamento quadrático (Figura 3). O maior número de folhas foi de 11,37 , estimado com a dose de $29,1 \mathrm{~g} \mathrm{~L}^{-1}$ de polímero, o que correspondeu ao aumento de $15,2 \%$ sobre o número de folhas emitidas nas mudas que não receberam a aplicação do polímero hidroabsorvente.

A ausência de efeito do polímero sobre o número de folhas pode ser atribuída à incorporação do lithothamnium, que pode ter favorecido a emissão de folhas, inclusive nas plantas que não receberam a aplicação do polímero, pois, nessas plantas, o número de folhas observado foi maior quando comparado àquelas sem a adição do lithothamnium.

De forma similar aos resultados apresentados em relação ao comprimento da parte aérea, houve efeito das doses de polímero sobre a matéria seca da parte aérea avaliada, sendo observado, nas mudas do substrato com adição de lithothamnium, os melhores resultados. Nessas mudas, o acréscimo de $64,6 \%$, com 139,1 mg de matéria seca, foi alcançado com a dose de 45,7 $\mathrm{g} \mathrm{L}^{-1}$ do polímero, enquanto o incremento obtido naquelas sem a adição do lithothamnium foi de 55,9\%, com $124 \mathrm{mg}$ de matéria seca, estimado com a dose de $39,8 \mathrm{~g} \mathrm{~L}^{-1}$ do polímero.

Aumentos na matéria seca também foram constatados em mudas de cafeeiro (Azevedo et al., 2002), relacionado com o vigor de crescimento devido à incorporação de polímero hidroabsorvente.

A presença do efeito do polímero sobre a matéria seca está em desacordo com os resultados obtidos por vários autores, que relataram decréscimos na produção de matéria em plantas de crisântemo (Sita, 2005), de cafeeiro (Vallone, 2003) e de tangerineira 'Cleópatra' (Vichiato et al., 2004), cultivadas com polímero hidroabsorvente, sendo esse comportamento atribuído à deficiência em aeração do sistema radicular.

Essa variação em relação aos efeitos da aplicação do polímero com potencial hidroabsorvente pode indicar a necessidade de reduzir a freqüência ou a quantidade de água a ser aplicada, pois os resultados negativos da sua aplicação foram atribuídos à deficiência de aeração do sistema radicular causado pelo excesso de umidade. Segundo Vichiato et al. (2004), o uso de polímero permite que a reposição de água ao solo seja mais espaçada, sem causar estresse hídrico às plantas que comprometa seu crescimento e o acúmulo de matéria seca.

Em relação à matéria seca das raízes (Figura 5), as mudas que tiveram acrescidas ao substrato a adição do lithothamnium, apresentaram aumento de $83,5 \%$, com $83,5 \mathrm{mg}$ de matéria seca nas raízes, resultado alcançado com a dose de $47,6 \mathrm{~g} \mathrm{~L}^{-1}$ do polímero hidroabsorvente. Para as plantas que não receberam a inclusão do lithothamnium, a dose que correspondeu ao maior valor estimado foi $35,3 \mathrm{~g} \mathrm{~L}^{-1}$ do polímero, com 75,5 mg de matéria seca nas raízes, o que representou aumento de $49,8 \%$. Resultados semelhantes foram observados por Azevedo et al. (2002), estudando a eficiência de polímero no fornecimento de água para o cafeeiro.

A diferença em relação ao acúmulo da matéria seca das raízes nas mudas que receberam a aplicação do lithothamnium, pode ser atribuída ao maior número de raízes secundárias formadas. Essa elevação pode ser devida às melhores condições nutricionais proporcionadas pela incorporação do lithothamnium ao substrato, o que também justifica o maior acúmulo de matéria seca na parte aérea (Figura 4).

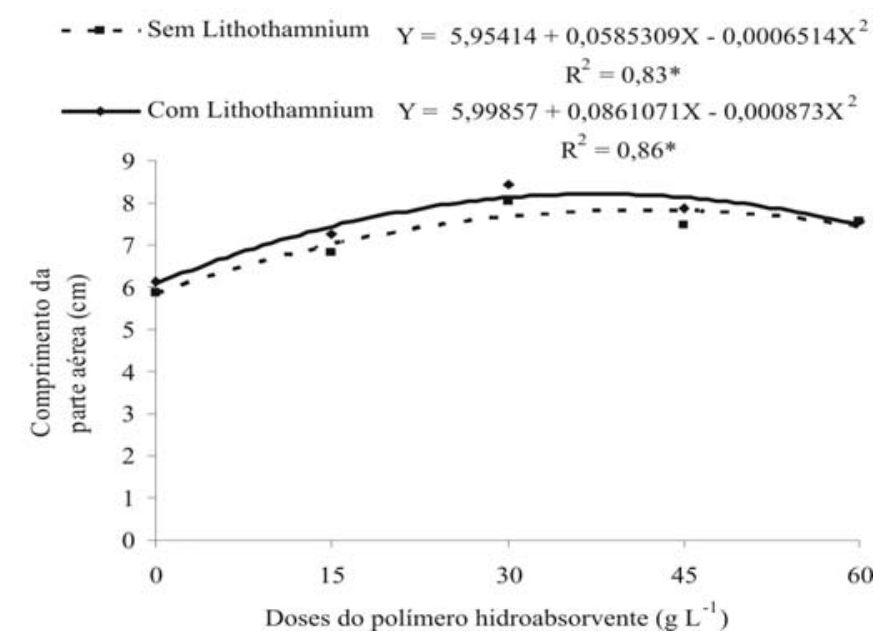

FIGURA 1 - Comprimento da parte aérea da tangerineira 'Cleópatra', em função da adição de doses do polímero hidroabsorvente e do lithothamnium ao substrato. 


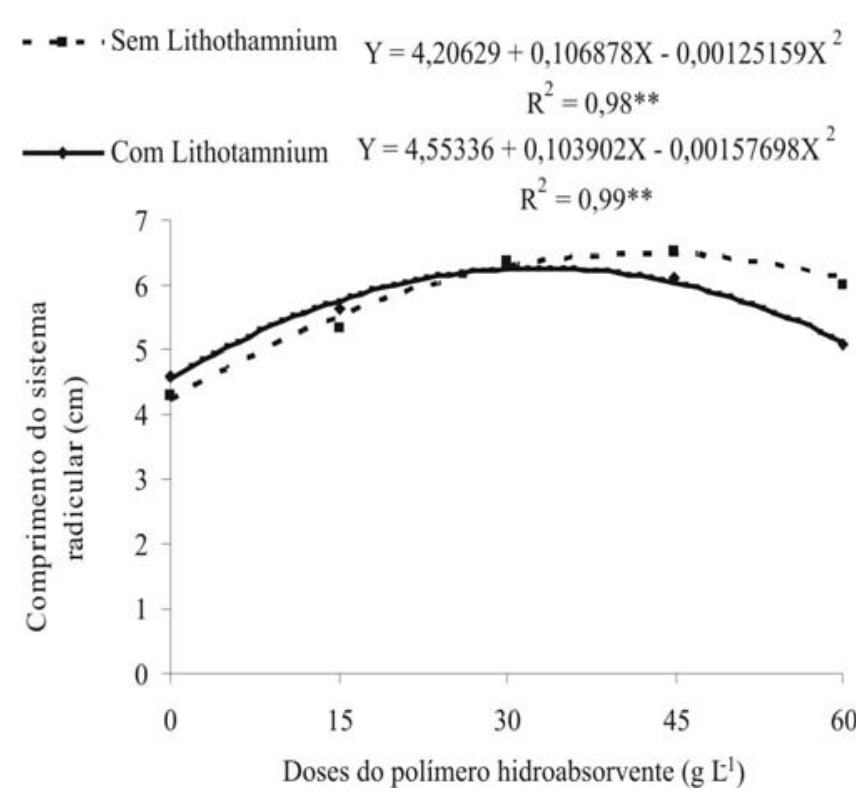

FIGURA 2 - Comprimento do sistema radicular da tangerineira 'Cleópatra', em função da adição de doses do polímero hidroabsorvente e do lithothamnium ao substrato.

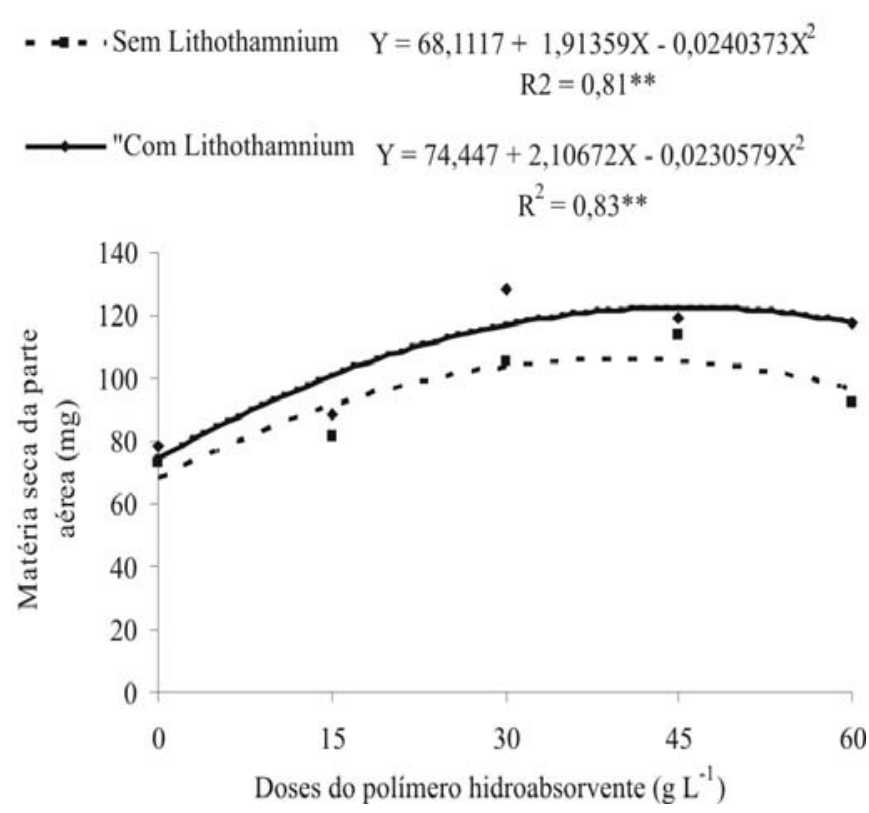

FIGURA 4 - Matéria seca da parte aérea da tangerineira 'Cleópatra', em função da adição de doses do polímero hidroabsorvente e do lithothamnium ao substrato.

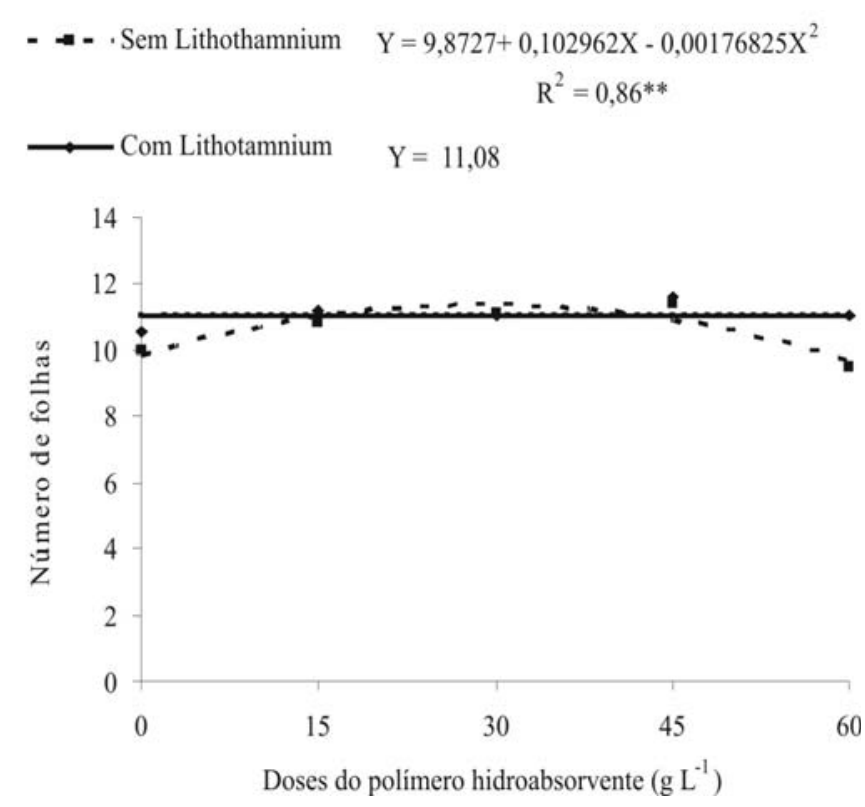

FIGURA 3 - Número de folhas da tangerineira 'Cleópatra', em função da adição de doses do polímero hidroabsorvente e do lithothamnium ao substrato.

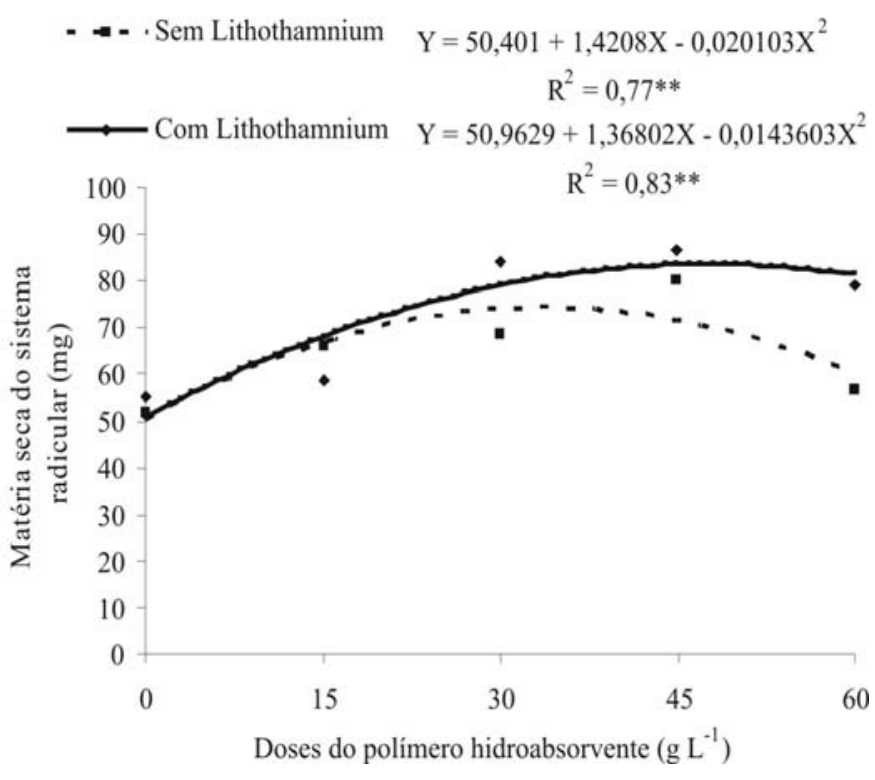

FIGURA 5 - Matéria seca do sistema radicular da tangerineira 'Cleópatra', em função da adição de doses do polímero hidroabsorvente e do lithothamnium ao substrato. 


\section{CONCLUSÕES}

1-A incorporação do polímero hidroabsorvente ao substrato favoreceu o desenvolvimento de porta-enxertos de tangerineira 'Cleópatra'.

2-A dose de polímero utilizada não deve ultrapassar 50 $\mathrm{g} \mathrm{L}^{-1}$ para evitar o excesso de umidade no substrato e a deficiência de aeração do sistema radicular.

3-A adição do Lithothamnium ao substrato de cultivo proporcionou o melhor desenvolvimento das mudas.

\section{REFERÊNCIAS}

AZEVEDO, T. L. F.; BERTONHA, A.; GONÇALVES, A. C. A.; FREITAS, P. S. L., FRIZZONE, J. A. Níveis de polímero superabsorvente, freqüência de irrigação e crescimento de mudas de café. Acta Scientiarum, Maringá, v. 24 n.5. p.1239-1243, 2002.

LAMONT, G.P.; O’CONNELL, M.A. Shelf-life of bedding plants as influenced by potting media and hydrogels. Scientia Horticulturae, Amsterdam, v.31, p.141-149, 1987.

MAUST, B. E.; WILLIANSOM, J. G. Nitrogen nutrition of containerized citrus nursery plants. Journal of American Society for Horticultural Science, Alexandria, v. 119, n. 2, p. 195-201, 1994.

MELO, P. C. de; FURTini NETO, A. E. Avaliação do Lithothamnium como corretivo da acidez do solo e fonte de nutrientes para o feijoeiro. Ciência e Agrotecnologia, Lavras, v. 27, n. 3, p. 508-519, 2003.
MENDONÇA, V.; ORBES, M. Y.ABREU, N. A. A.; RAMOS, J. D.; TEIXEIRA, G. A.; SOUZA, H. A. Qualidade de mudas de maracujazeiro-amarelo formadas em substratos com diferentes níveis de lithothamnium. Ciência e Agrotecnologia, Lavras, v. 30, n. 5, p. 900-906, 2006.

OLIVEIRA, R.A.; REZENDE, L.S.; MARTINEZ, M.A.; MIRANDA, G.V. Influência de um polímero hidroabsorvente sobre a retenção de água no solo. Revista Brasileira de Engenharia Agrícola e Ambiental, Campina Grande, v.8, n.1, p.160-163, 2004.

SITA, R. C. M. REISSMANN, C. B.; MARQUES, R.; OLIVEIRA, E.; TAFFAREL, A. D. Effect of polymers associated with $\mathrm{N}$ and $\mathrm{K}$ fertilizer sources on Dendrathema grandiflorum growth and $\mathrm{K}, \mathrm{Ca}$ and $\mathrm{Mg}$ relations. Brazilian Archives of Biology and Technology, Curitiba, v.48, n.3, p.335-342. 2005

VALLONE, H. S. Produção de mudas de cafeeiro (Coffea arábica L.) em tubetes com polímero hidrorretentor, diferentes substratos e adubações. 2003. 75 f. Dissertação (Mestrado em Agronomia-Fitotecnia) - Universidade Federal de Lavras, Lavras, 2003.

VICHIATO, M.; VICHIATO, M. R. M.; SILVA, C. R. R. Crescimento e composição mineral do porta-enxerto tangerineira 'Cleópatra' cultivado em substrato acrescido de polímero hidrorretentor. Ciência e Agrotecnologia, Lavras, v. 28, n. 4, p. 748-756, 2004. 